\title{
An Alternative Inactivant for Rift Valley Fever Virus using Cobra Venom-derived L-Amino Oxidase, which is Related to its Immune Potential
}

\author{
Ebtesam M Al-Olayan ${ }^{1}$, Aly F Mohamed ${ }^{2}$, Manal F El-Khadraqy ${ }^{1,3}$, Rania I Shebl ${ }^{4}$, \\ HanryMYehia ${ }^{5,6 *}$. \\ ${ }^{1}$ Chair Vaccines Research of Infectious Diseases, Faculty of Science, King Saud University, Riyadh, KSA.; ${ }^{2}$ Holding \\ Company for Production of Sera, Vaccines and Drugs, Cairo, Egypt; ${ }^{3}$ Department of Zoology \& Entomology, \\ Faculty of Science, Helwan University, Cairo,Egypt; ${ }^{4}$ Department of Microbiology and Immunology, Faculty of \\ Pharmacy, Ahram Canadian University (ACU), Cairo, Egypt; ${ }^{5}$ College of Food and Agricultural Sciences- \\ Department of Food Science and Nutrition, King Saud University, Riyadh, Saudi Arabia; ${ }^{6}$ Faculty of Home \\ Economics-Department of Food Science and Nutrition, Helwan University, Cairo, Egypt.
}

\begin{abstract}
Vaccine improvement depends on the formulation, adjuvant type and inactivant used. The type of formulation may interfere with immunogenicity. The present work aimed to evaluate the inactivation activity and related immune potential of the Cobra venom-derived LAO enzyme compared to the currently used inactivants (BPL and formalin) for both animal and human vaccines. The RVF virus was completely inactivated within 6 hrs, 4 hrs and 2 hrs after treatment with Formalin, $L A O$ and BPL, respectively. The vaccine potency $\left[E D_{50}\right]$ was arranged in a descending order from formalin (0.016) to BPL (0.005) and LAO (0.002). The total IgG levels, Neutralizing Index (NI) and Interferon levels were significantly increased compared to those detected after immunization with the BPL-and Formalininactivated vaccine candidates.
\end{abstract}

Key words: Rift Valley fever, inactivant, humoral immunity, interferon, interleukins, LAO.

\footnotetext{
*Authors for correspondence: hanyyehia43@yahoo.de
} 


\section{INTRODUCTION}

Rift Fever Virus was identified a century ago. It is a member of the Bunyaviridae family and the genus phlebovirus; its size ranges from 80 to 110 $\mathrm{nm}$, with 3 segmented (L, M, S) single-stranded, negative sense RNA genomes and a single serotype. The disease was described in Kenya in 1910-12. In 1930, it was isolated from sheep in Kenya. By 1944, it was isolated from the Semliki Forest in Uganda. There was large outbreak in South Africa in 1950-1. RVFV is a zoonotic disease and was identified as a fatal human disease in South Africa in 1976. Moreover, it reached Egypt in 1979-1980, and 200000 or more individuals were infected and 600 deaths recorded. In addition, the disease passed to Madagascar in 1979. In the $21^{\text {st }}$ century, RVF appeared in Saudi Arabia and Yemen, and 200 deaths recorded. It reached Sudan by 2007 (Paweska, 2008). The symptoms differ according to the age, species and breed of the animal. RVF viral infection can result in high rates of mortality in newborn animals and abortions in adults (CDC, 2007). It is characterized by biphasic fever, anorexia and lymphadenopathy, followed by weakness and death within 36 hours. In addition, Hemorrhagic diarrhea or abdominal pain is also observed; the mortality may reach $90 \%$ to $100 \%$ in newborns. The same symptoms are observed young calves, , with $10 \%$ to $70 \%$ mortality (Meegan and Bailey, 1988; Swanepoel and Coetzer, 2004). Abortions are the most frequent symptoms in adult sheep and cattle. In addition, fever weakness, mucopurulent nasal discharge, hemorrhagic, melena or foulsmelling diarrhea may occur in adult sheep (Vialat et al. 2000). RVF has economic impacts, as it affect animals then transmits to humans, causing fever accompanied by ocular complications. Two types of RVFV vaccines are available, prepared in VACSERA and Abbassia Research Institute (ElKaramany et al. (1981) . Both are formalininactivated vaccines that are prepared using different strains: Menya-sheep258 and ZH-501, respectively. The limitations of the current vaccines include a short-duration immune potential and the need for a booster dose (Mohamed et al. 1996). According to previous reports, vaccine antigenicity and immunogenicity is related to the virus inactivant used (Mohamed et al., 1996; Blackburn and Besselaar, 1991). Therefore, it is important to identify an alternative inactivant / virucidal agent with rapid inactivation efficacy, higher safety measures and no adverse effects. the virucidal activity of LAO has been previously demonstrated (Alyan et al. 2014), indicating that both snake and scorpion venoms and even LAO enzyme tended to exhibit more virucidal potential compared to the antiviral potential. For example VSV was completely inactivated within $6 \mathrm{hrs}$ post treatment with most of tested venoms and their derivatives such as LAO enzyme, Also, HSV-II- titer was depleted by $50 \%$ post treatment with Cerastes cerastes and Naja nigricollis and $65 \%$ for the other test venoms $6 \mathrm{hrs}$ post treatment. Therefore, the present work aims to evaluate LAO as alternative virucidal agent to current used formalin and BPL. Also, evaluation of the immune potentials of the LAO and BPL prepared vaccines compared with to the current formalin-inactivated vaccine.

\section{MATERIAL AND METHODS}

\section{Rift Valley Fever strain (RVFV)}

The RVFV pan tropic Menya Strain (Menya/Sheep/258) was kindly provided by Dr. Aly Fahmy Mohamed G.M. of the Applied Research Sector, VACSERA, Egypt. The strain had a titer of $10^{7.5} / \mathrm{ml}$ of the mice intraperitoneal lethal dose $\left(\mathrm{MIPLD}_{50} / \mathrm{ml}\right)$.

\section{RVFV cell lysate Ag preparation}

RVFV was diluted to final dilution of 1:100 in Hank's balanced salt solution (GIBCO- USA). The growth medium was poured off. Twenty $\mathrm{ml}$ of virus was added to each roller bottle and allowed to adsorb for 60-90 minutes. The bottles were rotated on the roller apparatus (Belco, USA) at 5 $\mathrm{rpm}$, followed by the addition $200 \mathrm{ml}$ of maintenance medium to each roller bottle. The bottles were incubated for the indicated times or until the CPE grade was equal to $+3-+4$. The cells were scraped from the RD walls with rubber policemen scraper, followed by decantation into 200-ml centrifuge bottles, and then centrifuged at $8,000 \mathrm{RPM}$ for $10 \mathrm{~min}$ at $4{ }^{\circ} \mathrm{C}$. The pellet was resuspended in borate saline, $\mathrm{pH} \mathrm{9,} \mathrm{in} 50 \mathrm{ml}$ Oak Ridge tubes. The pellet was rewashed and pelleted by centrifugation at $12,000 \mathrm{RPM}$ at $4{ }^{\circ} \mathrm{C}$. The pellet was re-suspended in borate saline solution, pH 9, 1\%Triton X-100 (Sigma Chemical Co., USA), and $1 \%$ SDS (BIO-RAD). The pellet was sonicated in a cup horn apparatus until the 
particulate matter had dispersed, and then centrifuged at 12,000 RPM in a cold centrifuge (Jouan, France). The supernatant was collected in a polypropylene tube, and the pellet was discarded. The antigen was aliquoted into labeled tubes and stored at $-70{ }^{\circ} \mathrm{C}$ (Mohamed et al., 1996).

\section{RVFV titration}

The RVF virus was titrated in mice according to the procedure described by Mohamed 1997; ElKaramany and Imam (1981), and the median infective dose was calculated as previously described (Reed and Muench 1938). using the following equation: Index $=(\mathrm{A}-50 \%) /(\mathrm{A}-\mathrm{B}) \mathrm{X}$ Log dilution (10), where $\mathrm{A}$ is the percentage of death at the dilution immediately above $50 \%$ and $B$ is the percentage of death at the dilution immediately below $50 \%$. Then, the index was applied to the dilution that produced the percentage of death immediately above 50 percent.

\section{Cell line}

The CCL- 81 Vero cells were kindly provided by the cell culture department, virology sector, VACSERA, Giza, Egypt. The cell line was supplied at passage no. 147. Fetal calf serum, the trypsin solution, and growth culture medium (199) supplemented with HEPES buffer and $200 \mathrm{mM}$ Lglutamine were supplied by Sigma Chemical Co. (St Louis, MO, USA).

\section{Virus seed Stock preparation}

The growth medium was discarded and replaced with $5 \mathrm{ml}$ of fresh medium containing $10 \%$ FCS and 100 MICLD $_{50}$ RVFV that was sterilely harvested from mouse brains, and the flasks were incubated in a $\mathrm{CO}_{2}$ incubator (Jouan, France) for one hour. Tissue culture flasks infected with RVFV were shaken at 15 min intervals to ensure that the virus was well distributed, and then 100 $\mathrm{ml}$ of maintenance media were added to each bottle. The inoculated bottles were microscopically observed each day for 7 days to detect the cellular changes and the development of a cytopathic effect (CPE). Cultures exhibiting a CPE grade of 2 or more were considered positive or infected. CPE grades $1,2,3$ and 4 were classified as $25,50,75$ and $100 \%$ changes in the cells, respectively. The flasks that developed a cytopathic effect (CPE) were frozen and thawed three times to release the virus from the cells (Bussereau et al. 1982).

\section{Chemical inactivants}

\section{[A]-Beta Propiolactone}

Beta Propiolactone was kindly supplied by Sigma -Aldrich (USA) in a lyophilized form at $100 \mathrm{mg} /$ vial and was stored in dark brown bottles.

\section{[B ]-L- Amino acid Oxidase (LAO)}

LAO was kindly supplied by Sigma Aldrich (USA) as lyophilized product at $10 \mathrm{mg}$ in dark colored vials. After its cytotoxicity was evaluated, it was used as $0.4 \mu \mathrm{g} / \mathrm{ml}$ and dissolved in cell culture medium (199-with Earle's Salts)

[C]- Formalin Formalin was supplied at 37-40 \% by Sigma-Aldrich (USA).

\section{Inactivation of RVFV}

$\beta$-Propiolactone ( $\beta \mathrm{PL}$ ), L-Amino Oxidase (LAO) and Formalin were used at $0.0035 \mathrm{M}, 0.4 \mu \mathrm{g} / \mathrm{ml}$ and $0.2 \%$, respectively. Their inactivation kinetics were determined as previously described (Mohamed et al. 1996; Abd el-Razek et al. 2011; Heba Ali Abd El-Guid et al. 2010; Zedan et al. 2011). The samples were collected after treatment to determine the virus titer at the indicated time points using cell culture assay.

\section{Mice}

Six- to eight-week-old outbred male Swiss Webster mice were housed at a fixed temperature of $25-27{ }^{\circ} \mathrm{C}, 12$ hours of light per day and 55-65\% relative humidity $(\mathrm{Rh})$ at the animal facility of the Egyptian Holding Company for Biological Product and Vaccines (VACSERA, Giza, Egypt). The mice were fed on pelleted chow composed of $11.2 \%$ moisture, $25.4 \%$ protein, $4.8 \%$ crude fibers, $8.5 \%$ ash, and $3.4 \%$ fat, and acidified tap water was supplied ad libitum. The mice were used according to the recommendations of the Animal Care and Use Committee (ACUC).

\section{RVFV vaccine Potency (Effective Dose end point - $\left(\mathbf{E D}_{\mathbf{5 0}}\right)$}

The potency of the inactivated RVF viral vaccine candidates prepared using different chemical inactivants, namely $\beta \mathrm{PL}$ and LAO and Formalin, was evaluated using the mouse immunization assay (MIA), as previously described (Elkaramany 1981; Salama 1991 ; Abd Razek et al. 2011). The effective dose of vaccine that can protect $50 \%$ of the infected mice was measured as follows: the experimental vaccine batches were 
serially diluted 5 -fold $(1 / 5-1 / 625)$ by adding sterile PBS, pH $7.2 \pm 2$, to the concentrated vaccine. Approximately $0.3 \mathrm{ml}$ of each dilution was inoculated intraperitoneally $(\mathrm{I} / \mathrm{P})$ in groups of 16 21-day-old weaned mice. Another set of 16 mice was used as negative controls. One week later, the mice were inoculated with the second dose of the vaccine diluted as described above. Fourteen days after the first challenge, a dose of $0.1 \mathrm{ml}$ containing $1000-10000$ MIPLD $_{50}$ was inoculated I/P. Five weaned mice from the negative control group were challenged in the same way, and the rest of control mice group were used as negative controls. The animals' mortality was recorded over 14 days and the potency of the inactivated RVF virus vaccines was determined.

\section{Immunization of Mice}

Four groups of mice $(20$ each $)$ were subcutaneously immunized. The groups of mice were immunized with $0.2 \mathrm{ml}$ of the Formalin-, BPL- and LAO-inactivated RVFV vaccine candidates. The fourth group was inoculated using $0.2 \mathrm{ml}$ of Normal saline as a negative control group. The immunized groups were bled through the retro orbital plexus. The blood samples collected from each group were collected at 1week intervals after immunization. The samples were tested to determine the antibody and cytokines levels (Mohamed et al. 1996; Blackburn and Besselaar 1991; Abd el-Razek et al. 2011)

\section{Immune sera preparation}

The individually collected blood samples were incubated for 30 minutes at $37^{\circ} \mathrm{C}$ to coagulate the blood, and then incubated overnight at $4{ }^{\circ} \mathrm{C}$ to retract the blood clots. The collected blood samples were centrifuged for 15 minutes at 3500 rpm using a cold centrifuge (KR412, Jouan, France). The sera were placed in empty tubes and re-centrifuged for another 10 min to remove any remaining blood clots or red blood cells. The collected sera were aliquoted and stored at $-80{ }^{\circ} \mathrm{C}$ until use according to (El-Karamany et al. 1981; Blackburn and Besselaar 1991; Abd el-Razek et al. 20117).

\section{Cell lysate RFv antigen}

The growth medium was poured off of the TC flask (Roller Bottle). RVFV was inoculated using the MOI, and the roller bottles were incubated for $1 \mathrm{hr}$ at $37^{\circ} \mathrm{C}$ for viral adsorption. Sufficient maintenance medium (75/100) was added to each
TC flask type to cover the cell surface. The infected Roller flasks were examined using an inverted microscope to detect the cytopathic effect $(\mathrm{CPE}$ at $+2 / 3)$. The cells were scraped using a cell scraper (TPP). Cell-free virus present in the maintenance medium was centrifuged with the scraped cells at 8000 RPM for 15 minutes at $+4{ }^{\circ} \mathrm{C}$ (Jouan-Ri-22). The supernatants were harvested and inactivated using Beta Propiolactone (SigmaAldrich, USA). The cell pellets were re-suspended in borate saline, $\mathrm{pH} 9$, in 15-50 $\mathrm{ml}$ tubes according to the cell pellet size/volume and then centrifuged at 12000 RPM for 10 minutes. The cell pellet was treated with a total volume of $20 \mathrm{ml}$ of $1 \%$ Triton $\mathrm{X}-100$ and $0.1 \%$ SDS in borate saline, $\mathrm{pH}$, and then sonicated in ice bath until no visible cell debris remained. The lysed cells were centrifuge at 12000 RPM for 10 minutes in a cold centrifuge, dispensed in sterile labeled cryotubes at $1 \mathrm{ml} /$ tube, and then stored at $-70{ }^{\circ} \mathrm{C}$.

\section{Borate saline preparation}

The solution was prepared using $160 \mathrm{ml}$ of $1.5 \mathrm{M}$ $\mathrm{NaCl}$; (87.66 gm), $200 \mathrm{ml}$ of $0.5 \mathrm{M}$ Boric acid (30.9 gm) and $47 \mathrm{ml}$ of $1 \mathrm{M} \mathrm{NaOH},(40 \mathrm{gm})$. The volume was adjusted to 2 Liters and the $\mathrm{pH}$ was adjusted to 9 using $\mathrm{NaOH} / \mathrm{n} \mathrm{HCL}$.

\section{Detection of the anti- RVFV antibody}

The antibody levels after immunization were determined as previously described [6-10], where the sera samples were diluted $1 / 20$ in dilution buffer (Phosphate-buffered saline pH 7.2 -Bovine serum Albumin, Sigma, USA). The serially diluted preparations were dispensed into ELISA plates (Nunc, USA) that were pre-coated with the RVFV cell lysate antigen. The plates were incubated for 1 $\mathrm{hr}$ at $37^{\circ} \mathrm{C}$ and then washed using washing buffer (PBS-0.05\% Tween 20). Approximately $0.1 \mathrm{ml}$ of an anti-mouse conjugate was added to plates at a final dilution of 1/1000; the plates were incubated and washed as previously described. A color reagent (Substrate buffer $\mathrm{A}+\mathrm{B}$ mixed equally (KBL, Switzerland) was dispensed into the plates. The plates were incubated in the dark for 10 minutes. The color development was stopped using 2 Normal $\mathrm{H}_{2} \mathrm{SO}_{4}$ (Sigma, USA). The antibody titer was determined using the following equation:

Titer $=$ OD Test $/$ OD reference $X$ the concentration of the reference 


\section{Cytokine determination}

The IFN- $\gamma$ and IL-5 levels were determined using specific sandwich ELISA kits for both items according to the manufacturer's protocol (BD Biosciences Pharmingen, San Diego, USA). Briefly, the high protein binding ELISA plates were coated with $100 \mu \mathrm{l} / \mathrm{well}(2.5 \mu \mathrm{g} / \mathrm{ml})$ of the monoclonal anti-mouse IFN- $\gamma$ and anti-IL-5 capture antibodies (all from BD Biosciences Pharmingen, San Diego, USA) for at least $18 \mathrm{hr}$ at $4{ }^{\circ} \mathrm{C}$ in carbonate/bicarbonate coating buffer $(1 \mathrm{~L}$ $\mathrm{H}_{2} \mathrm{O}$ containing $0.07 \mathrm{M} \mathrm{Na}_{2} \mathrm{CO}_{3}$ and $0.173 \mathrm{M}$ $\mathrm{NaHCO}_{3}, \mathrm{pH}$ 9.6). The excess antibodies were washed twice for 5 min each using washing buffer (PBS with 0.05\% Tween-20); the free wells containing no antibody were blocked with 200 $\mu \mathrm{l} /$ well of blocking buffer (PBS $+0.03 \%$ Tween 20 $+5 \%$ non-fat milk) (Kroger, Cincinnati, Ohio) and incubated for one $\mathrm{hr}$ at $37^{\circ} \mathrm{C}$. The plates washed 3 times as described above. One hundred $\mu 1 /$ well of the samples, controls and standards were dispersed in triplicate wells. Ten serial dilutions of the recombinant cytokines (starting from $2000 \mathrm{pg} / \mathrm{ml}$ ) were created with assay diluent (PBS+0.03\% Tween $20+1 \%$ non-fat milk) to generate a standard curve using. The assay diluent served as the blank. The plates were incubated for $2 \mathrm{hr}$ at room temperature then washed 3 times as described above. One hundred $\mu 1 /$ well of the biotinylated anti-mouse IFN- $\gamma$ antibody was added for detection. After incubating the plates for one hour at $37{ }^{\circ} \mathrm{C}$, the plates were washed and 100 $\mu 1 /$ well of a $1 / 1000$ final dilution of peroxidaseconjugated Streptavidin (Jackson ImmunoResearch) were added. The plates were incubated for one hour at $37{ }^{\circ} \mathrm{C}$, washed 4 times, and $100 \mu \mathrm{l} /$ well substrate (TMB - Kirkegaard) was added. After ten minutes of incubation at RT, the reaction was stopped using $100 \mu \mathrm{l}$ of $0.1 \mathrm{~N}$ $\mathrm{HCl}$. The yellow color that developed was measured using the UV max ELISA plate reader (Molecular Devices Corporation, USA) at $450 \mathrm{~nm}$. The mean values of the standards, samples and controls were calculated. The concentrations of the samples were calculated from the standard curve plotted for each cytokine. The average of triplicates of the controls were then subtracted from the samples and the results were presented as the delta concentration for each cytokine.

\section{Neutralizing index (NI)}

The NI was determined as previously described (Mohamed et al. 1996), where the positive sera were mixed with 10-fold serial dilutions of RVFV. The virus/serum mixture was incubated for 1-1.5 $\mathrm{h}$ at $37^{\circ} \mathrm{C}$. The virus-negative sera mixture was incubated as well. The two sets were dispensed to the Vero cells cultured on 96-well plates (Costar, USA). The plates were incubated for $1-1.5 \mathrm{~h}$ at $37^{\circ} \mathrm{C}$. The dilutions of the Virus-positive serum and Virus-negative serum mixtures were discarded and normal medium was dispensed into the entire plate. The plates were incubated for 7 days. The virus titers in the test groups were determined as previously described (Reed and Muench 1938). The titers of the Virus-positive serum and virusnegative serum mixtures were subtracted. The differences represent the neutralizing index (NI).

\section{Statistical analysis}

The data collected from repeated experiments that were conducted under the same conditions but at different times were pooled. All of the results were presented as the differences between the stimulated groups and the control groups. The means were reported for each group of mice $(n=20 /$ group). The comparisons between the different groups were analyzed using one-way analysis of variance (ANOVA) and the Student's t test.

\section{RESULTS}

\section{RVF virus Inactivation}

Chemicals were used to inactivate the Vero cellderived RVF virus that was separated into three aliquots. Three different inactivants, Formalin, Beta Propiolactone [BPL] and L-Amino Oxidase [LAO] were used at concentrations of $0.2 \%, 00035$ $\mathrm{M}$ and $0.4 \mu \mathrm{gm} / \mathrm{ml}$, respectively. The inactivation kinetics were determined in cell culture. The data recorded showed that the RVF virus was completely inactivated within 6 hrs, 4 hrs. and 2 hrs. after treatment with Formalin, LAO and BPL, respectively. The depletion rate of the virus infectivity titer was $0.123 \log (10) / \mathrm{min}, 0.064$ $\mathrm{TCID}_{50} / \mathrm{min}$ and $0.135 \mathrm{TCID}_{50} / \mathrm{min}$, and $0.11 \mathrm{log}$ (10)/min after treatment with Formalin, Beta Propiolactone and LAO, respectively. (Fig. 1) 


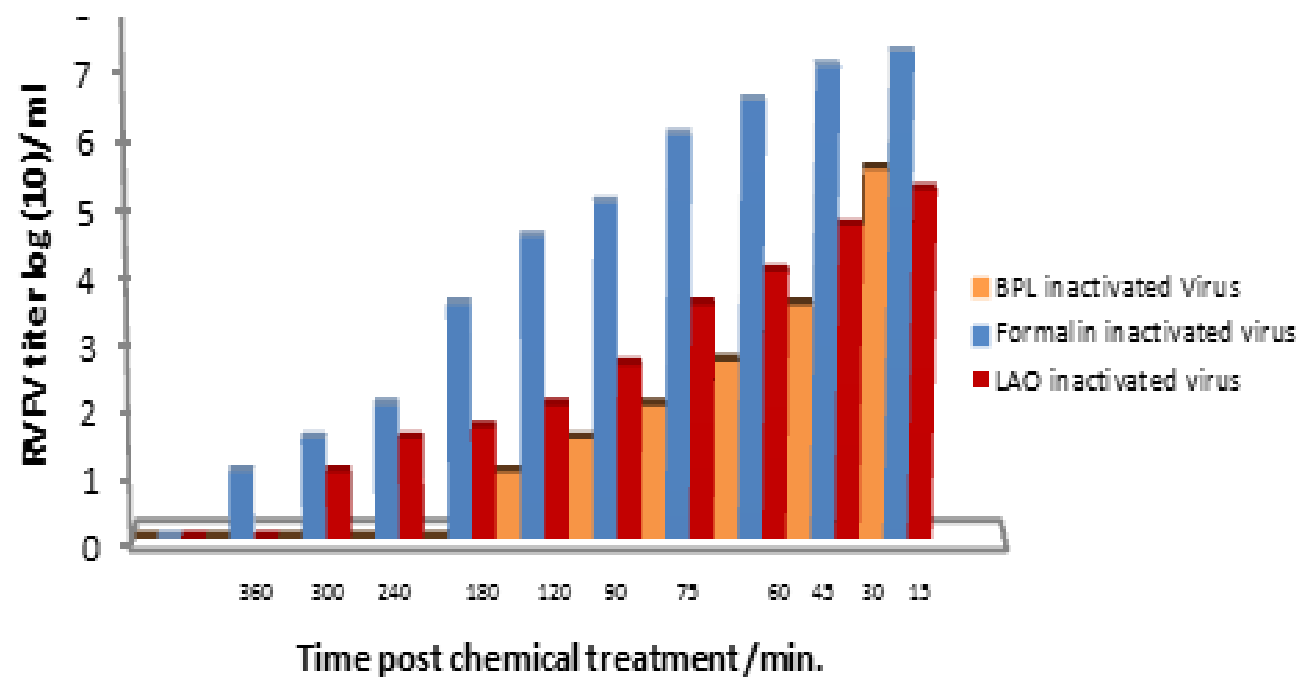

Figure 1- Inactivation kinetics of Rift Valley Fever Virus (RVFV) post treatment with different inactivants to time using cell culture assay.

\section{RVFV vaccine potency $\left(\mathbf{E D}_{\mathbf{5 0}}\right)$}

Regarding the immune potential of the prepared experimental Rift valley fever viral vaccines, the effective dose that protected $50 \%$ of challenged mice $\left[\mathrm{ED}_{50}\right]$ was evaluated using the mouse immunization-challenge assay, and it was found that the $\mathrm{ED}_{50}$ of the Formalin-, BPL- and LAO- inactivated vaccines were $0.016,0.002$ and 0.005 $\mathrm{ml}$. Thus, it was clear that the antigenicity was associated with the inactivant, where the ED50 of the LAO-inactivated vaccine was twice that of the BPL-inactivated vaccine and more than 12 times more potent than the Formalin-inactivated vaccine (Fig- 2)

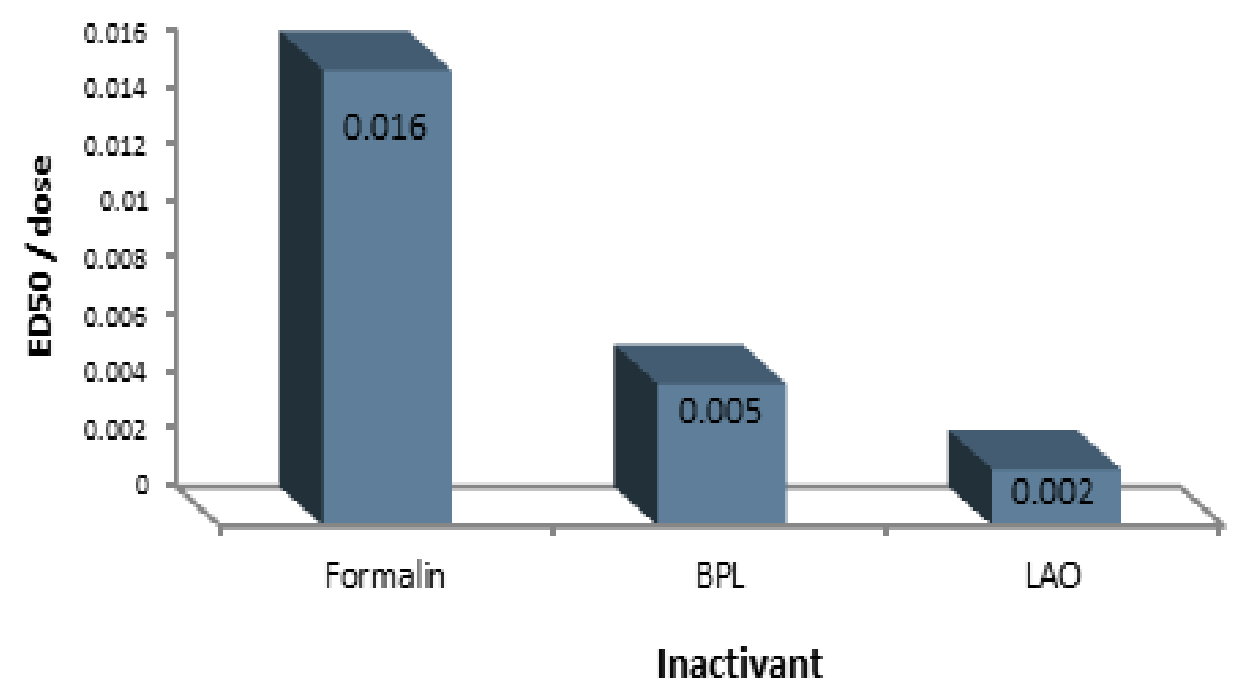

Figure 2- Evaluation of effective dose of rift valley fever vaccine candidates [ED50] using mice inoculation assay.

The data revealed that antibodies against the RVFV vaccines that were prepared using different inactivants could be detected 3 days after immunization and the peak $\mathrm{Ab}$ levels were detected 6 weeks after immunization with the LAO-inactivated vaccine and eight weeks after immunization with the BPL-inactivated vaccine. There was a significant difference in the Ab levels in the mice immunized with the LAO-inactivated vaccine $(\mathrm{P}<0.05)$ compared to the mice immunized with the BPL-inactivated vaccine, and the $\mathrm{Ab}$ levels in the mice immunized with the LAOinactivated vaccine were longer lasting than in those immunized with the BPL-inactivated vaccine (Fig. 3). 


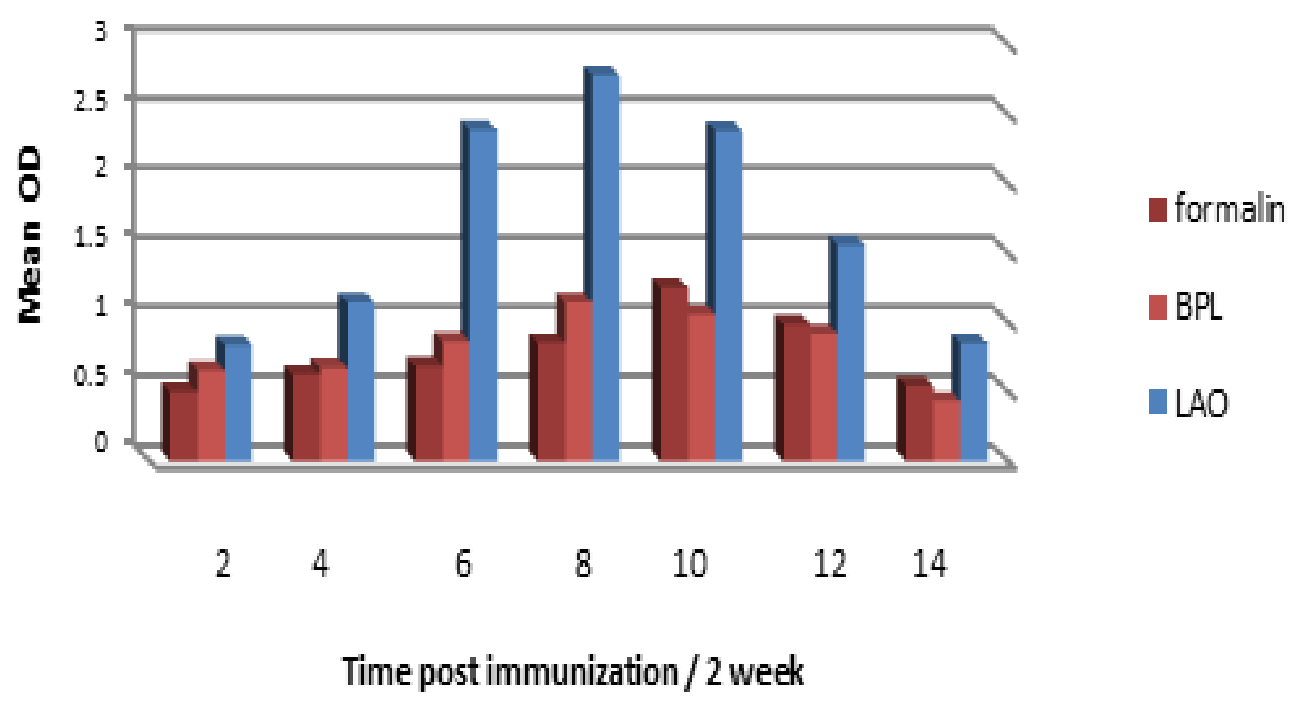

Figure 3- Evaluation of antibody titer using ELISA post immunization with inactivated vaccine candidates relatively to time.

Evaluation of the Neutralizing Index (NI) in the mouse sera samples

The immuno-reactivity of the BPL- or LAOinactivated vaccines were compared to the

formalin-inactivated vaccine and the results showed that the ni could be detected at 7 days after immunization in cell culture. The data revealed that the NI of the LAO-inactivated vaccine was significantly higher than those detected after immunization with the BPL- and formalininactivated vaccines $(\mathrm{P}<0.05)$. The peak NI values were observed at 8 and 10 weeks for the LAO-, BPL- and Formalin-inactivated vaccines, respectively (Fig. 4).

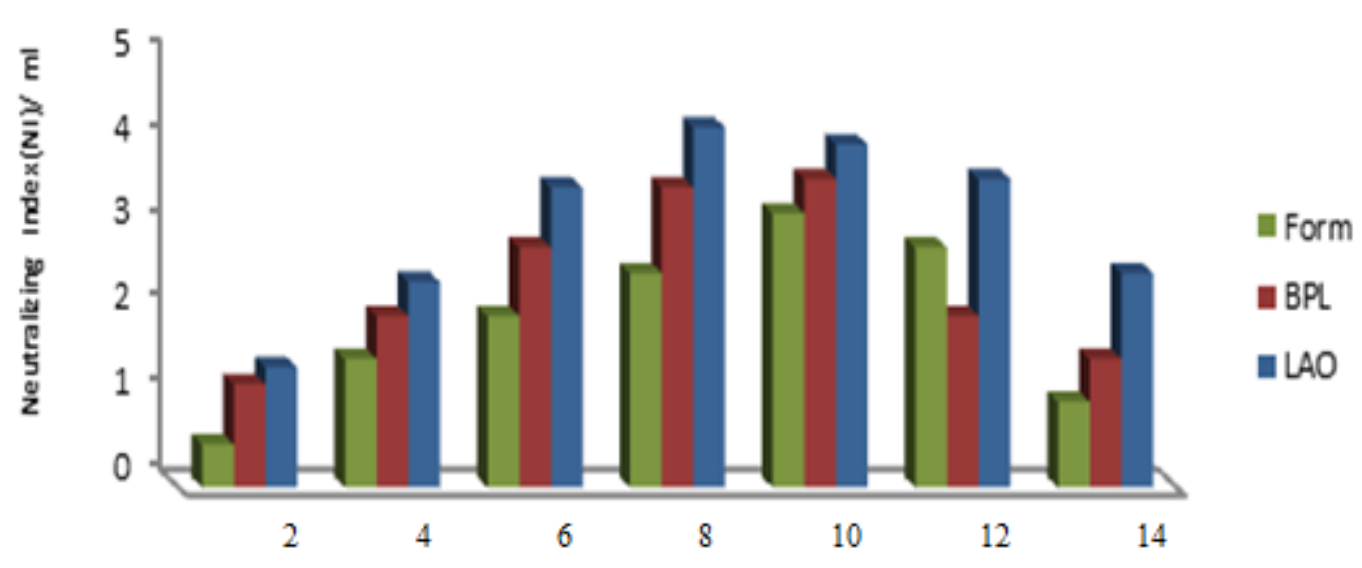

Time post immunization $/ 2$ weeks

Figure 4- Evaluation of neutralizing index (NI) post immunization with inactivated Rift Valley Fever candidates using cell culture assay relative to time. 
In the same way, the immune mediators (cytokine model) interferon and IL-5 were traced throughout the experiment. The levels of IFN and IL-5 exhibited almost the same trend as the antibody levels, where the IFN and IL-5 levels detected after immunization with the LAO-inactivated vaccine were significantly higher than those detected after immunization with the Formalinand BPL-inactivated vaccine candidates $(\mathrm{P}<0.05)$, (Figures. 5-6).

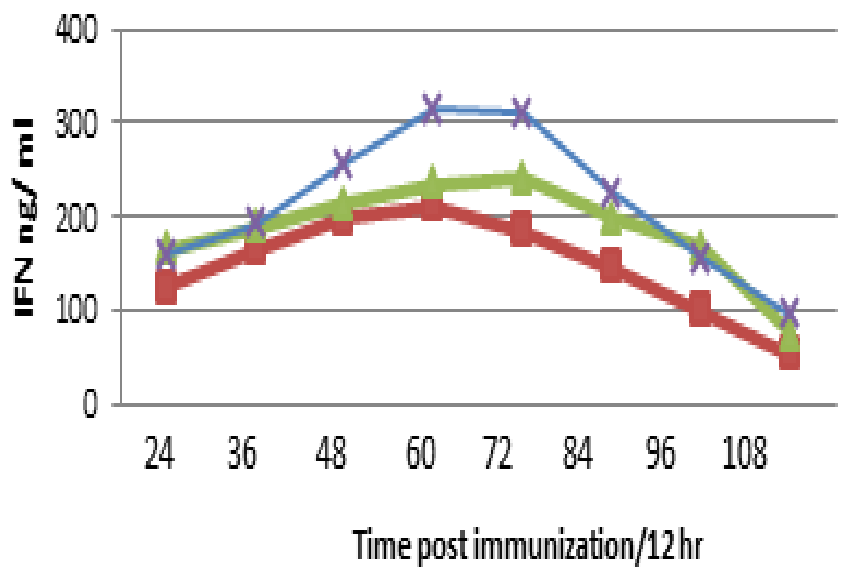

Figure 5- Evaluation of interferon gamma post immunization with inactivated RVFV using ELISA relative to time vaccine candidates.

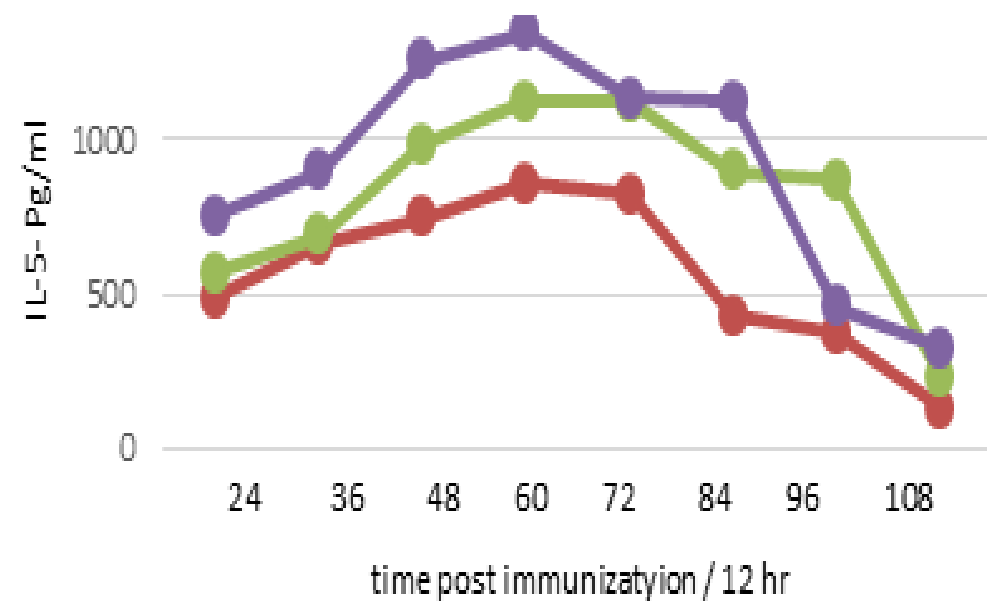

Figure 6- Evaluation of IL-5 post immunization with inactivated RVFV vaccine candidates using ELISA relative to time.

\section{DISCUSSION}

Rift Valley Fever is considered one of the most important zoonotic viral diseases, in Africa, as it affects both livestock and humans (Nina et al. 2009). Rift valley fever virus (RVFV) is transmitted to humans through mosquito bites. The RVFV symptoms include acute fever and occasionally retinal or hepatic complications with hemorrhagic signs. The incubation period of the fever usually lasts for 1 week. Generally, patients with this infection can easily recover, but less than five percent of patients can develop complications. These complications include encephalitis, retinopathy, or disseminated intravascular coagulation, leading to hemorrhage and even death (Balkhy and Memish 2003). The RVFV vaccines produced by either VACSERA or the Abbassia Vet. Research Institute are formalin-inactivated vaccines, although the two institutes used different strains, namely $\mathrm{ZH}-501$ and $\mathrm{M} / \mathrm{S} / 258$, and produced different formulations of the vaccines that do or do not include an Alum adjuvant. The deleterious effects of formalin as inactivating 
agent are well known (El-Karamany et al. 1981; Mohamed et al. 1996; Salama 1991). Our tests used $0.0035 \mathrm{M}$ BPL and $0.4 \mu \mathrm{g}$ LAO. Based on the drawbacks of the concentrations of formalin that are currently used as an inactivating agent, this dose was still risky and exhibited low antigenicity due to the deterioration of antigenic epitopes. Formalin can induce a depleted viral epitope configuration, leading to the loss of compatibility with the cell receptors that suppress the cell-virus interaction, as well as a low immune response (Blackburn and Besselaar 1991) .

The LAO enzyme is highly specific for L-amino acids, and, generally, hydrophobic amino acids are the best substrates. LAAO is a flavoprotein consisting of two identical subunits, each with a molecular mass of approximately $60 \mathrm{kDa}$. The purified enzymes are glycoproteins containing 3$4 \%$ carbohydrates. The de-glycosylation of the enzyme did not alter its enzymatic activity, but appeared to alter its pharmacological activities (Iwanaga and Suzuki 1979). Snake venoms are perhaps the richest sources of the enzyme. Snake venom LAAOs are generally very active and are widely used to prepare $\alpha$-keto acids because of their chemo- and stereospecificity (Szwajcer 1982; Findrik et al. 2006). The $\alpha$-Keto acids of essential amino acids are useful therapeutic agents for certain diseases. Recently, snake venom LAAO has become an interesting object for biomedical studies because of its antimicrobial, anti-HIV, anticoagulant, platelet aggregationinducing and inhibiting, apoptotic-inducing as well as anti-cancer activities. The amino acid sequences of snake venom LAAOs exhibit a high degree of homology. X-ray structural analysis of LAAO revealed a dynamic active site and the presence of 3 domains: a FAD-binding domain, a substratebinding domain and a helical domain. LAAOs were reported to exhibit moderately lethal toxicity and virucidal activity. Recent studies showed that LAAOs are multifunctional enzymes exhibiting edema-inducing, platelet aggregation-inducing or inhibiting, apoptosis-inducing as well as antibacterial, anti-coagulant and anti-HIV effects. These effects were primarily mediated by the $\mathrm{H}_{2} \mathrm{O}_{2}$ liberated during the oxidation process, but direct interactions between LAAO and the target cells that may play an important role. Snake venom LAAO is recognized as a multifunctional protein with promising biomedical applications. Several reviews on snake venom L-amino acid Oxidase have been published ( $\mathrm{Du}$ and Clemetson 2002).
Based on the previously recorded bioactivity of the LAAO, the present study used it as an inactivating agent and compared its activity with BPL, which is currently used for human and some animal vaccine preparations. LAAO not only showed a more rapid inactivating activity than BPL but also significantly increased the cellular and humoral immunity compared to the animals immunized with the BPL- and Formalin-prepared vaccines. The data agreed with a previous report (Shebl et al. 2012), that showed that LAAO has low antiviral activity and a very good virucidal activity against VSV and HSV-II, as the viruses could be completely inactivated within $6 \mathrm{~h}$ of treatment at $37^{\circ} \mathrm{C}$. Additionally, BPL has been used for human vaccine production and it showed a better antigenicity in the RVFV vaccine, and, in turn, the vaccine potential was improved, despite the expense and hazardous effects of BPL exposure (Zedan et al. 2011). The inactivation of RVFV may be attributed to the oxidizing stress of LAAO, as the high-resolution X-ray structure of the enzyme revealed the presence of a channel that would direct the $\mathrm{H}_{2} \mathrm{O}_{2}$ product to the exterior surface of the protein near the glycan moiety at Asn172. The glycan moiety is thought to be involved in the LAAO-target cell interaction. This may explain the ability of LAAO to localize the $\mathrm{H}_{2} \mathrm{O}_{2}$ to the targeted cells. A better understanding of the pharmacological actions of LAAOs will facilitate the application of snake venom LAAOs in the design of anti-cancer and anti-HIV drugs, as well as drugs for the treatment of infectious diseases caused by parasites, such as leishmaniasis. Accordingly, these findings were the basis for using LAAO as a virucidal agent to prepare an improved RVFV vaccine and why we tried to analyze the inactivation efficiency of the cobra venom enzyme derivative on the enveloped RVFV virus and its related antigenicity. The cytotoxicity of LAAO agreed with a previous report (Shebl et al. 2012), which showed that LAAO exhibited significant cytotoxicity in different cancer cell lines and normal Vero cells at concentrations higher than $0.4 \mu \mathrm{g} / \mathrm{ml}$. The cytotoxicity was attributed to $\mathrm{H}_{2} \mathrm{O}_{2}$ release, which enhanced the oxidative stress in cell nucleus and caused cell death and progressive apoptosis. Meanwhile, the inactivation efficacy of LAAO was longer lasting than BPL and shorter than Formalin at $4 \mathrm{hrs}, 2 \mathrm{hrs}$ and $6 \mathrm{hrs}$, respectively, which has been shown several authors (Shebl et al. 2012; El-Karamany 1987; - Mohamed 2006; 
Abd el-Razek et al. 2011; Heba et al. 2010 ). In addition, the related vaccine potency $\left(\mathrm{ED}_{50}\right)$ recommended by the WHO must be less than 0.02 $\mathrm{ml}$. The vaccine potential was evaluated by the immune potential, as cellular immune parameters were detected within $24 \mathrm{hrs}$ and Abs were detected at 7 days after immunization, respectively. These parameters were significantly increased and longer lasting in the mice immunized with the LAAOinactivated vaccine compared to those immunized with the BPL- and Formalin-inactivated vaccines. The LAO-inactivated vaccines have not been compared for use as an enzyme model to prepare vaccines, while the BPL-prepared vaccines were potentially active, as previously reported (Abd elRazek et al. 2011; Heba et al. 2010; Zedan et al. 2011). BPL is known to have a faster inactivation efficacy compared to Formalin and BEI (Mohamed et al. 1996; Blackburn and Besselaar 1991). It is well known that the ED50 values vary according to the inactivating agents; BPL showed a higher vaccine potency than other inactivants. This was attributed to the limited effect on the configurations of the viral epitopes to which the antigenicity is attributed, and it also had no deleterious effect on the immune response, as $\mathrm{CF}$ and HI antibody titer not affected post immunization. Moreover, the BPL concentration used for inactivation is virus-type dependent (Blackburn and Besselaar 1991) In addition to previous reports (Mohamed et al. 1992; Zedan et al. 2011;- Madhusudana et al. 2004; Abd el-Razek et al. 2011; Heba et al. 2010); BPL showed a better $\mathrm{Ab}$ profile than the Formalin- and Ascorbic acid-inactivated polio and RVFV vaccines. Meanwhile, the Ab levels were evaluated using the Neutralizing index values (NI) and compared to the release after immunization with the BPLinactivated vaccine. The sera samples contained potentially active neutralizing antibodies that was more than 2 (NI), these data were parallel to a previous report (Mohamed et al. 1996), that showed that the NI of a BPL-inactivated RVFV vaccine was higher than that detected after immunization with a formalin-inactivated vaccine; the NI values ranged from 3-3.5. Additionally, the present data were in accord with previous reports (Wun et al. 2010; Khirat et al. 1994), although these authors used different vaccine strains, namely the MP-12 live attenuated strain and the formalin-inactivated ZH (501) vaccine. Moreover, the IFN and IL-5 levels were associated with the inactivant and peaks were reached at 21 and 14 days after vaccination with the LAO-, and BPLand Formalin-inactivated vaccines, respectively. These data were in accord with the study by Gohar et al. (2008), unpublished data and (Abd el-Razek et al. (2011), who showed that the neutralizing antibodies could be detected 2 weeks after immunization with both the live attenuated strain and the inactivated strain. Regarding both $\mathrm{Nab}$ and IFN, Gohar et al. 2008, demonstrated that the neutralizing indices (NI) were detected in sera samples collected 2 weeks after immunization with the Formalin- and Ascorbic acid-inactivated RVF vaccines using $\mathrm{M} / \mathrm{S} / 258$ strain, and the maximum level was reached three and four months after immunization. The NI and IFN and IL-5 levels were significantly higher after the administration of the AA-RVFV vaccine compared to the F-RVFV vaccine. A secondary increase was detected after challenge of the immunized groups of mice. The IFN peak occurred at 28 days after immunization, the IL-5 peak occurred at 21 days after vaccination, and the $\mathrm{Ab}$ levels and cellular parameters tested were attributed to the type of inactivant used. The effective doses of the prepared experimental vaccines in the present study were related to the inactivant, as previously reported (Blackburn and Besselaar 1991), and better than that recommended by the WHO vaccine committee, which states that the $\mathrm{ED}_{50}$ must be less than 0.02 $\mathrm{ml}$ of vaccine, as measured by vaccine potency. The BPL- and LAAO-prepared vaccine candidates displayed $\mathrm{ED}_{50}$ values as good as those detected by others authors (Gohar et al. 2008), where the $\mathrm{ED}_{50}$ of the AARVFV-prepared vaccine was two-fold less than $(0.006 \mathrm{ml})$ the FRVFV-prepared vaccine $(0.011 \mathrm{ml})$. The group vaccinated with the AARVFV vaccine had a greater immune reaction than those vaccinated with the FRVFV vaccine, as evaluated using the NI and $\mathrm{PRNT}_{50}$. The vaccinated groups exhibited maximum levels of IFN- $\gamma$ at days 14 and 28 for the groups vaccinated with FRVFV and AARVFV, respectively. In addition, these groups exhibited maximum levels of IL-5 at days 21 and 14, respectively. Meanwhile, the data recorded in the present work agreed with a previous report (Mohamed et al. 1996), that showed that the $\mathrm{Ab}$ levels were inactivant-dependent. In addition, the authors used killed BCG bacteria as an adjuvant, but showed no significant effect on the immune response, which was attributed to the reduced concentrations of the cell membrane-dependent adjuvant MDP. 
Moreover, the Abs were detected using MIA, a cell culture neutralization assay and plaque reduction assays, but not ELISA. Additionally, in the present work, the ELISA was used to detect the antibodies after vaccination and there are restrictions for using ELISAs, as previously reported (Jansen van Vuren et al. 2011). Different enzyme-linked immunosorbent assay (ELISA)based techniques for the detection of antibodies to Rift Valley fever virus (RVFV) have been developed in recent years, but their diagnostic sensitivity was not directly compared. In addition, their use might still be restricted to high biocontainment facilities, when sera to be tested are collected from viremic individuals. On the contrary, the Ab levels could easily be detected using cell lysate antigens prepared as previously described (Abd el-Razek et al. (2011), where the Abs could be detected after immunization with a $\mathrm{CPN}$-adsorbed vaccine and their levels were increased compared to those detected after immunization with the Alum-adsorbed vaccine. In addition, the IFN levels exhibited the same pattern; finally, it is possible that LAAO could be safely used as an inactivant and further investigations on both the cellular and humoral immunity in response to LAAO-inactivated vaccines and long term immunization studies should be performed.

\section{CONCLUSION}

It could be concluded that LAO was a good virucidal agent and equal to BPL, but its immune potential was better than BPL and it could induce long-lasting immunity. Moreover, the LAOinactivated vaccine should be investigated further to analyze its ability to induce humoral immunity, cellular mediators and adverse biochemical effects.

\section{ACKNOWLEDGEMENT}

This research project was supported by a grant from the "Research Center of the Center for Female Scientific and Medical Colleges", Deanship of Scientific Research, King Saud University.

\section{CONFLICT OF INTEREST}

The authors declared that there are no conflicts of interest regarding the publication of this manuscript.

\section{REFERENCES}

Abd el-Razek, NE, Sahar A S, Mohamed AF. Nanocapsulated Rift Valley Fever Vaccine Candidates and Relative Immunological and Histopathological Reactivity in Out Bred Swiss Mice. J Vac vaccine. 2011; 2:1.

Alyan MS, Shalaby MA, El-Sanousi AA, Mohamed AF et al. Antiviral and Anticancer Potentials of Snake and Scorpion Venom Derivatives. Inventi Rapid: Mol Pharma. 2014, Issue 2, [ISSN 0976-3856]

Balkhy HH, Memish ZA. Rift Valley fever: an uninvited zoonosis in the Arabian peninsula. Int $J$ Antimicrob Agents. 2003; 21:153-7.

Blackburn NK, Besselaar TG . A study of the effect of chemical inactivants on the epitopes of Rift Valley Fever virus glycoproteins using monoclonal antibodies. J Virol Methods. 1991; 33: 367-374

Bussereau F, Benejean J, Saghi N. Isolation and study of temperature-sensitive mutants of rabies virus. Gen Virol. 1982; 60 (pt1):153-8.

Centers for Disease Control and Prevention. Rift Valley fever outbreak in Kenya. MMWR Morb Mortal Wkly Rep. 2007; 56: p73-76.

Du XY, Clemetson KJ. Snake venom L-amino acid oxidase. Toxicon. 2002; 40: 659-665.10.

El-Karamany R, Imam I, Farid A. Production of inactivated RVF vaccine. J Egypt Publ Health Assoc. 1981; 56: p495-525.

El-Karamany, RM. Production in Vero cells of an inactivated rabies vaccine from FRV/K for animal and human use. Acta Virol. 1987; 31(4):321-328.

Findrik Z, Geueke B, Hummel W, Vasic-Racki D. Modeling of L-DOPA enzymatic oxidation catalyzed by L-amino acid oxidase from Crotalusadamanteus and Rhodococcusopacus. Biochem Eng J. 2006; 27: 275-286.

Heba AA, Hashem AE, Tayeb OE, Mohamed AF. Evaluation of inactivation efficacy of Sabin Polio virus using different inactivating agents and its immunogenicity post Nano and Micro Encapsulation. IJMR. 2010; 1(3): 114-122.

Iwanaga S, Suzuki TL. Amino acid oxidase. In: Lee CY ed. Handbook of experimental pharmacology. Berlin: Springer. 1979; 52: 75-84.

Jansen van Vuren P, Tiemessen CT, Paweska JT. Jansen van Vuren P, Tiemessen CT, Paweska JT. Antinucleocapsid protein immune responses counteract pathogenic effects of Rift Valley fever virus infection in mice. PLoS One.. 2011; 6 (9). 
Khirat E, Gihan, KM, Soar! MS, Mohsen AY, Aida E. Studies on RVFV. Trials for production of attenuated RVF variant from original (2M 501) Egyptian strain. $J$ Egypt Vet Med Assoc. 1994; 54:4.

Madhusudana SN, Shamsundar R, Seetharaman S.In Vitro inactivation of the rabies virus by ascorbic acid. Int J Infect Dis. 2004; 8: 21-25.

Meegan JM, Bailey CL. Rift Valley fever, p 5176 In Monath TP, editor. (ed), The arboviruses: epidemiology and ecology, 1989; vol 4 CRC Press, Boca Raton, FL.

Mohamed AF, El-Kaschef AH, Reda IM, Tantawey HM, Hassan RA. Biological studies for the importance of Rift Valley Fever Vaccine. Ph.D. thesis, Suez Canal Univ. Zool. Depart. 1996.

Mohamed.AF . Antioxidants Enhancement to the Immune Response of NIH Mice to Vero Cell Grown Rabies Virus Vaccine. Egypt J Hosp Med. 2006; 23: $363-370$.

Nina L, Jonas N, Ake L, Michele B, Clas A Goran B. Characterisation of immune responses and protective efficacy in mice after immunisation with Rift Valley Fever virus cDNA constructs. JVI. 2009; 6:6.

Paweska JT. Epidemiology of RVF: Potential Risks for introduction into

Europe. Lelystad, Netherlands 28 November 2008.

Reed LT, Muench HA. Simple method of calculating fifty percent end point. Am J Hyg. 1938; 27: p 493-8.

Salama LS. Studies on the immune response of Rift valley fever vaccine M. Vsc. Thesis VetMed. 1991; Cairo University.

Shebl RI, Mohamed AF., Ali A. E. . Amin MA.(): Antimicrobial Profile of Selected Snake Venoms and Their Associated Enzymatic Activities. Br Microbiol Res J. 2012; 2(4): 251-263.

Swanepoel R, Coetzer JAW. Rift Valley fever. In: JAW Coetzer, RC Tustin (eds). Infectious diseases of livestock. Volume 2. 2nd ed. Oxford University Press, Oxford, UK., 2004; 1037-1076.

Szwajcer E, Brodelius P, Mosbach K. Production of $\alpha$-keto acids. Part 2: Immobilized whole cells of Providenciasp. PCM 1298 containing L-amino acid oxidase. Enzyme Microb Technol. 1982; 4: 409-413.

Vialat P, Billecocq A, Kohl A, Bouloy M. The S segment of Rift Valley fever phlebovirus (Bunyaviridae) carries determinants for attenuation and virulence in mice. J Virol. 2000; 74: p15381543.

Wun-Ju S, Chris P, Edith L, et al. Pathologic Studies on Suspect Animal and Human Cases of Rift Valley Fever from an Outbreak in Eastern Africa. Am J Trop Med Hyg. 2010; vol. 83 no. 2 Suppl 38-42.

Zedan, MA, Mohamed FA, Tantawy HM, Amal SM. Comparative Evaluation of different enhancers to liquid Rabies vaccine at different thermal conditions. Egypt. J. Zool. 2003; 40:443-453.
Received: January 15, 2016; Accepted: May11, 2016 